\title{
O patrimônio arqueológico e a atividade turística na sesmaria jaguaribe, litoral Norte de Pernambuco
}

\author{
Vanessa Rodrigues* \\ Universidade Federal de Pernambuco (Brasil)
}

\begin{abstract}
Resumo: Este trabalho apresenta o diagnóstico do Patrimônio Arqueológico utilizado pela atividade turística na área da Sesmaria Jaguaribe, Abreu e Lima/PE. Nesta etapa foram avaliados os sítios arqueológicos São Bento e o Sítio Timbó, procurando, também, identificar se houveram ações de planejamento da atividade turística que está sendo desenvolvida na área. Foram propostas ações seguras e construtivas de melhorias para o uso do patrimônio arqueológico na atividade turística através do Turismo Arqueológico. A preservação do Patrimônio Arqueológico se trabalhada de forma planejada e adequada, torna-se uma ferramenta para proteção patrimonial dos sítios arqueológicos. Neste sentido considera-se necessário que o patrimônio tenha uma infraestrutura mínima para receber os visitantes e que não o descaracterize. Dessa forma, poderá transmitir conhecimento às demais gerações.
\end{abstract}

Palavras-chave: Sesmaria Jaguaribe; Turismo Cultural; Turismo Arqueológico.

Archaeological heritage and tourism activity in jaguaribe sesmaria, north coast of pernambuco

Abstract: This study presents a diagnosis of the Archaeological Heritage used by tourist activity in the area of Sesmaria Jaguaribe, Abreu e Lima/PE. At this stage the archaeological sites Sao Bento and Timbo were evaluated, searching either identify if there were actions in planning of tourism that is being developed. Safe and constructive actions for improvements were proposed to the use of the archaeological heritage in tourism through the Archaeological Tourism. The preservation of the Archaeological Heritage, if working in a planned manner, becomes a tool for asset protection of archaeological sites, therefore, it is necessary that the assets have minimal infrastructure for visitors so that they are not adulterated and continue to impart knowledge to other generations.

Keywords: Sesmaria Jaguaribe; Cultural Tourism, Archaeological Tourism.

\section{Introdução}

Os Sítios Arqueológicos estão despertando o interesse, não somente dos pesquisadores, mas, também, dos turistas e, consequentemente, do trade turístico - os empresários. Assim, surge o Turismo Arqueológico ou Arqueoturismo, atividade turística em sítios arqueológicos onde tanto os turistas quanto a população local pode perceber a importância do passado histórico da cidade ou destino turístico (Silva; Oliveira, 2012). Na Carta de Lausanne (1990) os sítios arqueológicos são descritos como:

A porção do patrimônio material para o qual os métodos de arqueologia fornecem conhecimentos primários. Engloba todos os vestígios da existência humana e interessa todos os lugares onde há indícios de atividades humanas, não importando quais sejam elas, estruturais e vestígios abandonados, de todo tipo, na superfície, no subs-solo ou sob as águas, assim como o material a eles associados (Carta de Lausanne, 1990:02).

O Turismo Arqueológico, segundo Beni (1998) é o "deslocamento de pessoas a sítios arqueológicos, escavações e cavernas com inscrições e pinturas rupestres". Nessa perspectiva encontra-se também o conceito de F. Manzato que define essa atividade como o:

Universidade Federal de Pernambuco, Brasil; E-mail: vanessrodrigues@hotmail.com 
[...] processo decorrente do deslocamento e da permanência de visitantes a locais denominados sítios arqueológicos, onde são encontrados os vestígios remanescentes de antigas sociedades, sejam elas pré-históricas e/ou históricas, passíveis de visitação terrestre ou aquática. (Manzato, 2005).

No Brasil verifica-se um grande potencial para este segmento no Nordeste, destacando-se o Parque Nacional da Serra da Capivara, no Piauí e o Bairro do Recife, em Pernambuco. Nessa área outros pontos estão surgindo, como é o caso da Sesmaria Jaguaribe, localizada no Litoral Norte de Pernambuco, que compreende atualmente os municípios de Igarassu, Paulista e Abreu e Lima.

$\mathrm{Na}$ Sesmaria Jaguaribe encontra-se as Ruínas da Capela de São Bento (Figuras 01 e 02) e o Forno de Cal (Figuras 03 e 04), patrimônio arqueológico foco desta pesquisa. Verifica-se que esse patrimônio encontra-se incluído em roteiros turísticos promovidos pelo poder municipal de Abreu e Lima, entretanto, está abandonado, cercado por lixo e mato. Dessa forma essa pesquisa teve por objetivo realizar o diagnóstico do Patrimônio Arqueológico nessa área, analisando a sua infraestrutura; a percepção dos moradores do entorno sobre a atividade turística e a preservação do patrimônio arqueológico; as ações de planejamento da atividade turística. Procura-se, portanto, propor ações de melhorias para o uso do patrimônio arqueológico para inserir essa área na atividade turística do Litoral Norte de Pernambuco.

\section{Metodologia}

Esta pesquisa possui um caráter exploratório, descritivo e qualitativo. De acordo com Almeida (2006, p. 27) "a pesquisa exploratória considera que existe uma relação entre o mundo e o sujeito que não pode ser traduzida em números". Severino (2012), acrescenta que esse tipo de pesquisa "busca apenas levantar as informações sobre um determinado objeto, delimitando, assim, um campo de trabalho, mapeando condições de manifestação desse objeto." (Severino, 2012, p. 123). Por outro lado, a pesquisa descritiva "possui quatro aspectos: descrição, registro, análise e interpretação de fenômenos atuais, objetivando o seu funcionamento no presente, e quantitativa pela quantidade representativa que será utilizada na análise da amostragem" (Freitas et al, 1999, p. 38). Silva (2008, p. 23) ressalta que as pesquisas descritivas são mais utilizadas pelo turismo e são recomendadas quando o objetivo da pesquisa "é a descrição sistemática, objetiva e precisa das características de uma determinada população ou área de interesse".

Questionários foram aplicados com diferentes objetivos. Para identificar se houve planejamento na implantação da atividade turística na área da Sesmaria Jaguaribe, selecionou-se o Secretário de Turismo e Cultura de Abreu e Lima e a Arqueóloga do IPHAN. Para verificar a percepção dos moradores do entorno da área de pesquisa sobre a preservação do Patrimônio Arqueológico foram aplicados questionários in loco. Por fim, para diagnosticar a infraestrutura dos sítios arqueológicos, foi elaborado e preenchido um protocolo de observação do Patrimônio Arqueológico, onde foram registrados os pontos positivos e negativos do estado de conservação das ruínas do São Bento, antiga fazenda dos beneditinos de Olinda, datada do século XVII e o Forno de Cal. Esse protocolo foi adaptado da proposta realizada por Manzato (2005). Dessa forma foi possível avaliar e propor ações de melhorias não impactantes para a proteção patrimonial.

\section{Resultados e Discussão}

A Igreja de São Bento (Figuras 01 e 02) foi construída nos cercados da "Fazenda de São Bento de Jaguaribe, do século XVII" (Oliveira; Lima, 2003, p.07), localizada no Sítio São Bento que pertencia a Ordem Beneditina de Olinda. Parte da igreja cedeu devido a ações antrópicas e naturais sendo possível notar uma torre e paredes laterais. E "próximo à igreja foram encontradas, por meio de escavações arqueológicas [...] o alicerce de outra edificação. Supõe-se ser a casa dos padres devido à sua estrutura e localização ao lado da igreja" (Oliveira; Lima, 2003, p. 08). A igreja "tem ainda a sua tipologia bem caracterizada nos restos de alvenaria existentes. Tudo indica, pelas condições nas quais as ruínas se apresentam, a possibilidade de sua reconstrução, por meio de um projeto arquitetônico a ser elaborado". (Carréra; Surya, 2008, p. 11).

Já, o Forno de Cal (Figuras 03 e 04) está localizado às margens do Rio Timbó, e foi registrado no IPHAN com o nome de Sítio Timbó. É "caracterizado pelas ruínas de uma arquitetura industrial, possivelmente, dos séculos XVIII e XIX” (Oliveira; Lima, 2003, p. 07). A área onde está inserido este 
sítio apresenta indícios da produção de cal, um dos fatores que "contribuíram para o desenvolvimento econômico do povoado no período colonial, o qual deu origem ao município" (Oliveira; Lima, 2003, p. 07).

Para que esse patrimônio seja preservado e sofra menos impactos diante da atividade turística, ações devem ser tomadas para que o Patrimônio Arqueológico seja considerado apto para a atividade do turismo. Em relação à infraestrutura será necessário tomar as seguintes providências: 1) implantação de grades protetoras, 2) implantações de lixeiras, 3) limpeza da área (Figuras. 05 e 06); 4) placas informativas e indicativas em dois idiomas; e, 5) monitores, preferencialmente pessoas da própria comunidade.

No inicio das pesquisas arqueológicas nessa área foi elaborada a proposta Programa Jaguaribe: Preservação Ecológica e Cultural da Sesmaria Jaguaribe (2001). Algumas medidas para o desenvolvimento do turismo foram definidas, entre elas a instalação de museus. Considera-se que a criação desses museus, para exposição de achados arqueológicos, seria uma forma importante para a preservação, divulgação, sendo mais um ponto atrativo para o desenvolvimento do turismo local.

\section{Figuras 01 e 02: Ruínas da Igreja de São Bento}
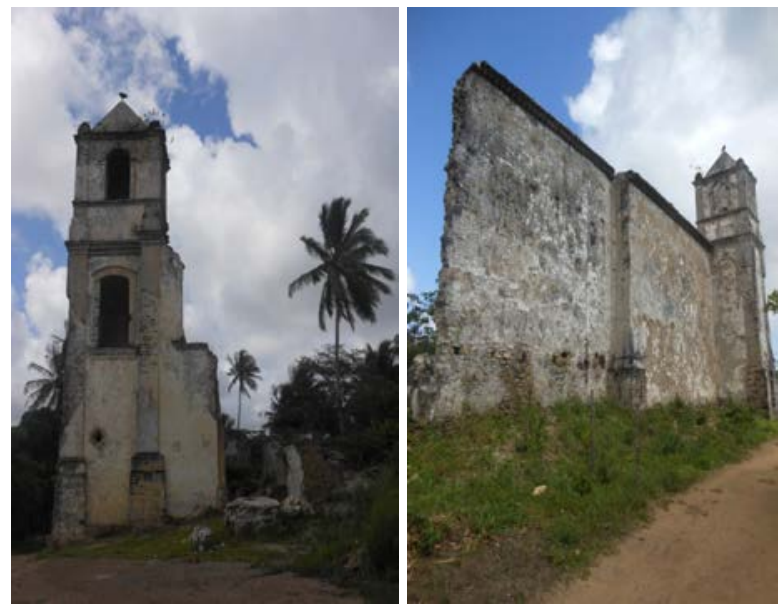

Fonte: Vanessa Rodrigues

Figuras 03 e 04: Ruínas do Forno de Cal
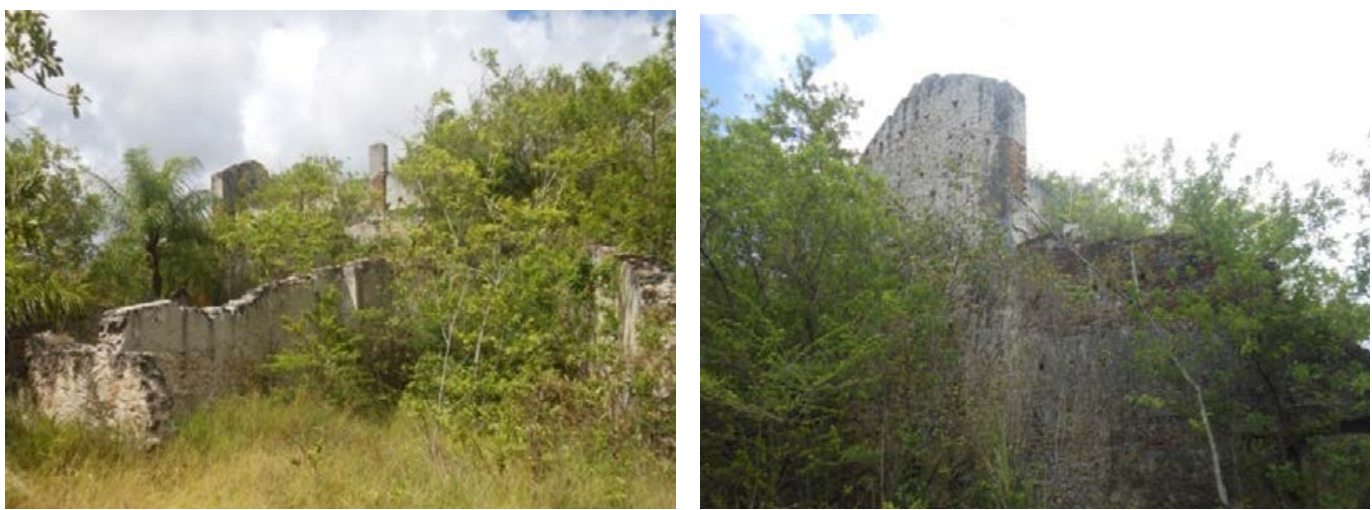

Fonte: Vanessa Rodrigues 


\section{Figuras 05 e 06: Lixo no entorno da Ruína de Forno de Cal}
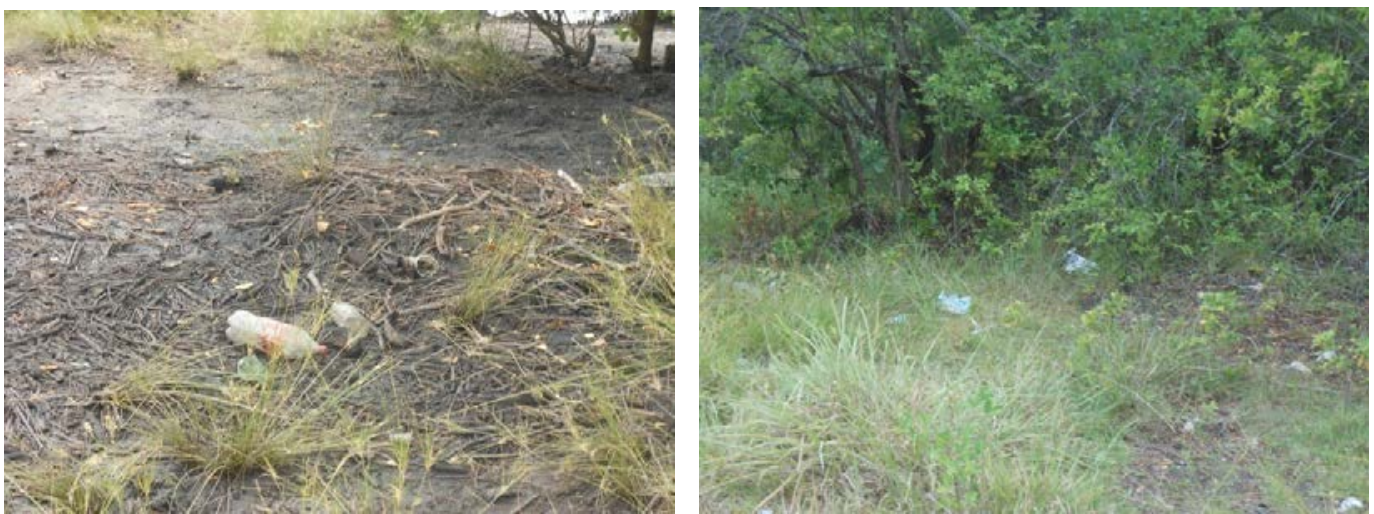

Fonte: Vanessa Rodrigues

Nos questionários do Secretário de Turismo de Abreu e Lima e da Arqueóloga do IPHAN, aplicados para identificar as ações que foram ou estão sendo realizadas para a preservação dos sítios arqueológicos e a sua utilização na atividade turística na Sesmaria Jaguaribe, verifica-se uma dicotomia nas respostas. O Secretário informa que houve planejamento turístico com foco na preservação do patrimônio e que havia comunicação direta com o órgão federal responsável pelo patrimônio, o IPHAN. Porém, a Arqueóloga do órgão informou não ter ciência das ações que estão sendo desenvolvidas na área, exceto daquelas citadas nos relatórios de intervenção arqueológica.

Para conhecer a percepção dos moradores sobre o Patrimônio Arqueológico e a sua preservação, na área do entorno dos sítios, trabalhou-se com uma amostra de 52 questionários válidos e foram realizadas, inicialmente perguntas no intuito de traçar o perfil dos entrevistados, assim a maioria dos moradores entrevistados (31\%) tem faixa etária entre 26 a 35 anos de idade, na maioria do gênero feminino (56\%), com escolaridade fundamental incompleto (31\%). Logo em seguida, foram aplicadas as perguntas voltadas à identificação da noção de patrimônio, preservação e turismo. Dessa forma, verificou-se que $75 \%$ dos moradores não têm conhecimento sobre as ações realizadas sobre preservação (Gráfico 01); 63\% não sabem da importância da preservação do patrimônio (Gráfico 02); e 85\% acreditam na importância do turismo para a área (Gráfico 03). Todos os entrevistados informaram que tinham interesse de saber das ações desenvolvidas na área, porém não foram e não são informados.

\section{Gráfico 01: Percepção dos moradores sobre ações de preservação}

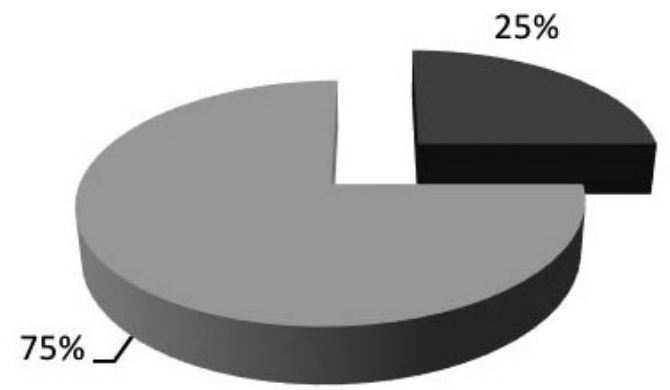

- Sim

Não

Fonte: Pesquisa de campo (2013) 


\section{Gráfico 02: Importância do patrimônio}

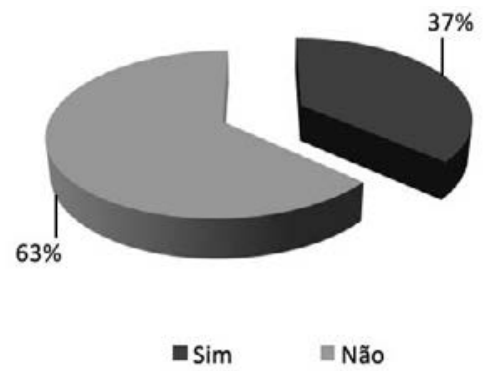

Fonte: Pesquisa de campo (2013)

\section{Gráfico 03: Importância do turismo para a área}

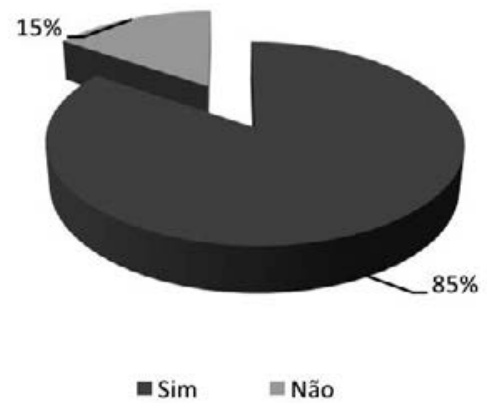

Fonte: Pesquisa de campo (2013)

\section{Considerações Finais}

O turismo é uma atividade dinâmica que modifica de forma veloz os lugares e atrai desenvolvimento local e social. Para transformar um local em destino turístico, não basta ter atrativos turísticos, deve-se, acima de tudo, planejar para que o Patrimônio presente não sofra danos irreversíveis. Os órgãos públicos precisam planejar os lugares para dispor a atividade turística, de forma que estes sejam sustentavelmente desenvolvidos.

A Sesmaria Jaguaribe, que possui uma riqueza patrimonial representada pelas ruínas da antiga fazenda dos beneditinos de Olinda e as ruínas do Forno da Cal, inseridas na mata atlântica, ainda encontra-se desconhecida pela população local, que desconhece o seu valor.

O poder público apesar de ter conhecimento do valor desse Patrimônio Arqueológico e do abandono da área, não soluciona os problemas. A gestão deveria ser responsável por preparar, fiscalizar e conservar os bens patrimoniais.

As ruínas da Igreja de São Bento e o Forno de Cal são exemplos do Patrimônio Arqueológico. Encontram-se praticamente abandonados e apesar de serem citados em revistas de turismo e estarem inclusos no roteiro de trilhas ecológicas, não foi realizado o planejamento estratégico adequado e implantação de infraestrutura para inseri-los no contexto do turismo: a) não foram protegidos com cercas para não serem destruídos; b) não limparam o entorno que possui lixo; c) não foram implantadas placas informativas (placas que expliquem o contexto histórico do patrimônio); d) e nem houve estudo de capacidade de carga. 
Não foram implantadas ações de inclusão do patrimônio arqueológico na atividade turística. Observa-se um desenvolvimento incipiente da atividade do turismo ecológico, mas as ruínas arqueológicas não estão de forma adequada no cenário, pois a infraestrutura é mínima.

A atividade turística para ser bem desenvolvida deve ter a aceitação dos moradores locais e para conseguir a adesão da maioria é necessário informá-los sobre a importância da preservação patrimonial e dos benefícios que podem ter com a prática do turismo. Além disso, é importante pensar em curso de capacitação para que os moradores tornem-se agentes preservadores e sejam inclusos na atividade turística de forma que obtenham uma renda extra através dessa atividade.

\section{Bibliografia}

AlmeidA, M. B.

Noções Básicas sobre Metodologia de Pesquisa Científica. DTGI-ECI/UFMG, 2006. Disponível em: $<$ http://mba.eci.ufmg.br/downloads/metodologia.pdf>. Acesso em: 14 de Jun. 2012.

Beni, M. C.

1998. Análise Estrutural do Turismo. $6^{a}$ ed. São Paulo: SENAC,

Carréra. M; Surya, L. A

Organização Espacial de uma Fazenda Colonial Beneditina: Reflexo da Estruturação Social Vigente. Anais do II Encontro Internacional de História Colonial. Mneme-Revista de Humanidades. UFRN. Caicó (RN), v. 9. n. 24, Set/out. 2008. ISSN 1518-3394. Disponível em <www.cerescaico.ufrn.br/ mneme/anais>.

Fonseca, J. J. S.

Metodologia da Pesquisa Cientifica. UECE. Ceará, 2002. Disponível em: <http://www.dqi.ufms.br/ lp4/ apostilaMetodologia.pdf>. Acesso em: 13 de Jun. 2012.

Freitas, H; Oliveira, M; Saccol, A. Z.

O método de pesquisa Survey. Revista de administração, São Paulo, v.35, p.105-112, julho/setembro 2000. Disponível em: <http://www.unisc.br/portal/upload/com_arquivo/o_metodo_de_pesquisa_survey. pdf>. Acesso em: 10 ago. 2013.

Instituto do Patrimônio Histórico e Artístico Nacional.

Carta de Lausanne. Brasilia, 1990. Disponível em: < http://portal.iphan.gov.br/portal/baixaFcdAnexo. do?id=262>. Acesso em: 25 mar. 2012.

Manzato, F.

Turismo Arqueológico: Diagnóstico e Análise do Produto Arqueoturístico. PASOS. São Paulo, v.5, n.1, p. 99-109, 2007. Disponível em: <http:// redaly.uaemex.mx/pdf/881/88150108.pdf>. Acesso em: 15 out. 2009

Oliveira, C; Lima, M. L.

2003. Novas perspectivas para o turismo no Litoral Norte de Pernambuco. Anais do VII ENTBL Encontro Nacional de Turismo com Base Local. Universidade Estadual de Santa Cruz, Ilhéus-BA.

Rodrigues, W. C.

Metodologia Cientifica. FAETEC/IST. Paracambi, 2007. Disponível em: <http://professor.ucg.br/SiteDocente/admin/arquivosUpload/3922/material/Willian\%20Costa\%20Rodrigues_metodologia_cientifica. pdf $>$. Acesso em: 14 de Jun. 2012.

Severino, A. J.

2012. Metodologia do trabalho científico. Editora Cortez, 23 ed. rev. e atual.

Silva, V. R; Oliveira, C. A.

2012. Atividade turística na cidade do Recife: Levantamento e Diagnóstico de Sítios Arqueológicos. Anais de Iniciação Cientifica (IC) XX CONIC / IV CONITI / VIII JOIC, UFPE

Silva, L. B. A.

2008. Turismo Histórico-Cultural em Recife-PE: um olhar sobre o Mercado de São José. Universidade Federal de Pernambuco, Recife/PE. 